\title{
DOMAIN PRIBADI DALAM PEMEROLEHAN DAN PENGGUNAAN BAHASA DI KALANGAN PENUTUR BAHASA JAWA (TINJAUAN SELINTAS ASPEK LINGUISTIK EDUKASIONAL)
}

\author{
Oleh :Susilo Supardo *
}

\begin{abstract}
Abstrak
Pemerolehan bahasa dan penggunannya ditentukan oleh latar belakang domain yang pernah dimasuki oleh setiap penutur bahasa. Yang paling esensial dalam kehidupan berbahasa individu adalah domain pribadi, tempat seorang penutur belajar dan memanfaatkan bahasa dengan segala fasilitas, lingkungan, dan ragam.

Yang termasuk ke dalam domain pribadi adalah keluarga, teman sebaya, teman bermain, dan kelompok akrab yang lain. Semua komponen tersebut dapat direfleksikan di dalam bahasa mereka.

Pengamatan atas fenomena yang dideskripsikan dalam tulisan ini dapat mengisyaratkan adanya fungsionalisasi bahasa yang terlihat pada kegiatan komunikasi, khususnya dengan kelompok sebaya (horisontal) dan kelompok generasi di atasnya (vertikal). Fenomena di atas dapat dijelaskan dalam kancah etnografi bahasa.
\end{abstract}

\section{A. Pendahuluan}

Setiap penutur suatu bahasa memiliki repertoire nya yang dihimpun sejak yang bersangkutan memiliki kesadaran dan kemampuan memperoleh bahasa tertentu. Reportoire tersebut ditentukan oleh lingkup keberadaan yang bersangkutan. Proses selanjutnya yang mengiringi pemerolehan bahasa adalah penggunaannya di dalam komunikasi. Sehubungan dengan pernyataan di atas, pada sektor ini perlu dikemukakan beberapa konsep yang didukung oleh sejumlah istilah teknis dalam pembicaraan berikut. Adapun konsepkonsep itu adalah yang tercantum pada istilah yang mendasari tekstur ini.

\section{Domain}

'Domain adalah suatu klaster dalam situasi sosial yang secara khas dibatasi oleh seperangkat kaidah tingkah laku bersama, yang terdiri atas peran para interlokutor di dalam setting yang khas ini dan topik yang

\footnotetext{
- Dosen Jurusan Pendidikan Bahasa dan Sastra Indonesia FPBS IKIP Yogyakarta
} 
mungkin sekali menjadi pembicaraan mereka (Penalosa, 1980 : 127). Apabila pada suatu ketika bahasa Jawa digunakan pada domain tertentu dan bahasa Indonesia di tempat yang lain di masyarakat tutur Jawa, di sini terjadi situasi diglosik. Sebaliknya, apabila domain itu tumpang tindih, bahasa Jawa pada umumnya memberikan kesempatan berperan kepada bahasa yang secara sosial berprestise dan dominan, yakni bahasa Indonesia.

\section{Domain Pribadi}

Pada dasarnya yang diistilahkan dengan domaian pribadi adalah situasi sosial yang lazimnya tidak menjadi perhatian atau pusat perhatian umum, oleh karena domain ini terutama melibatkan kelompok pertama, yaitu teman-teman dekat, karib atau hubungan-hubungan yang akrab (Penalosa : 1980). Kelompok jenis ini merupakan domain yang paling awal yang dihadapai oleh seorang penutur. Biasanya domain semacam ini tetap menjadi paling signifikan sepanjang hidupnya. Dalam mengkaji domain semacam itu orang harus memandang hubungan-hubungan di antara struktur bahasa, penggunaan bahasa, dan seting sosial yang secara langsung menjadi tempat tindak komunikasi terjadi. Dalam kaitan dengan ini, yang menjadi tumpuan pembicaraan adalah struktur dalam skala kecil yang hanya melibatkan beberapa pribadi, dan tidak menyangkut konteks sosial yang lebih luas.

\section{Penggunaan Bahasa}

Fenomena pertuturan baik dalam bentuk verbal maupun ortografis, merupakan aktualisasi produk pemerolehan bahasa oleh yang bersangkutan dan dikemas di dalam konteks sosial budayanya. Patut dicatat bahwa keragaman bahasa yang terlihat dalam penggunaan bahasa, ditentukan oleh penggunaan dan pengguna bahasa, tergantung pada faktor di mana digunakan, kepada siapa, dan siapa saja yang menggunakannya (Holmes, $1995: 246)$.

Dalam kaitan dengan masalah ini domain pribadi juga merupakan pendidikan bahasa secara tidak langsung bagi penuturnya. Hal ini terlihat pada saat yang bersangkutan harus berhadapan dengan interlokutor lain.

Pada saat menyampaikan pesan terlebih pada saat terjadi interaksi verbal, orang harus melakukan strategi penyesuaian yang lazim dinamakan konvergensi. Strategi ini berupa penyamaan register ataupun topik 
yang beroperasi di dalam pertuturan. Proses penyamaan ini lazim dinamakan akomodasi pertuturan (Holmes, 1995)

\section{B. Ekologi Bahasa}

Pembicaraan topik ini perlu memperhatikan juga masalah yang berada di sekitar proses pemerolehan dan penggunaan bahasa. Adapun halhal yang disebutkan di atas merupakan aspek yang sangat penting bagi kehidupan penutur bahasa. Hal demikain lazim dinamakan ekologi bahasa. Pada hakikatnya ekologi bahasa adalah kajian mengenai hubungan timbal balik antara pemakaian suatu bahasa dengan lingkungannya. Lingkungan pemakaian bahasa di sini mengacu penutur-penuturnya dan bahasa-bahasa yang ada di sekitarnya (Langgole, 1993 : 59)

Apabila dicermati lebih lanjut, sesungguhnya kondisi kebahasaan di dalam masyarakat tutur Jawa ini mengisyaratkan kemultibahasaan yang dapat terjadi. Hal demikian dapat diharapkan kehadiran penguasaan bahasa lain atau bahasa asing oleh warga masyarakat tutur Jawa ini.

Dalam pada itu perlu dicatat suatu kemungkinan peran bahasa Indonesia jika ditinjau dari ekologi bahasa, berupa peran melakukan kontak bahasa, baik antara bahasa Indonesia dan bahasa Jawa, bahasa Jawa dengan bahasa asing, maupun antara bahasa Indonesia dan bahasa asing. Fenomena demikian ini akan ikut mewarnai penggunaan bahasa oleh penutur bahasa Jawa. Selain itu, masih terdapat peluang lain di dalam masalah kontak bahasa ini. Apabila di masyarakat tutur tersebut terdapat bahasa lain, seperti bahasa Sunda di eks-kawedanan Majenang di kabupaten Cilacap, akan terjadi juga kontak bahasa Jawa dan bahasa Sunda (bahasa daerah lain) tersebut.

Mengingat pentingnya aspek bahasa yang demikian berpengaruh atas pembentukan penutur bahasa, khususnya masalah ekologi bahasa, berikut ini selintas dibicarakan masalah ini.

\section{Lingkungan Keluarga}

Yang terlihat dengan jelas dan tidak dapat dibantah adalah besamya keragaman di dalam pola-pola keluarga yang terdapat di antara keluarga Jawa. Kita dapat menduga akan adanya korelasi sosiolinguistik dalam keragaman ini pada struktur keluarga, yang sacara relatif lebih banyak berorientasi kepada penggunaan bahasa Indonesia di daerah kota besar, dan di dalam keluarga yang telah maju. Pada dasarnya yang akan dibicarakan 
di sini adalah suatu fakta yang menunjukkan bahwa lokasi pembelajaran bahasa pertama terutama adalah keluarga. Kondisi yang meliputi pembelajaran bahasa pertama yang berupa bahasa daerah atau bahasa Indonesia atau sebaliknya di lingkup keluarga, merupakan masalah intensnya yang bersangkutan di dalam hal tersebut. Ranah kepentingan atau perhatian dapat menjadi hal yang berkaitan dengan komposisi keluarga, seperti misalnya dampak atas bilingualisme yang terdapat pada nenek, bibi, paman, dan sejenisnya yang merupakan kelompok di luar keluarga inti. Dalam kaitan dengan ini yang harus diingat adalah repertoire dan kebiasaan linguistik orang tua dalam keluarga, tetap merupakan hal yang sangat penting.

\section{Masalah Sosialisasi}

Berbicara mengenai hal ini orang dapat menyatakan bahwa istilah sosialisasi mengacu berbagai macam proses, yakni pengajaran, peniruan, sanksi atas pelanggaran, dan sebagainya, yang digunakan oleh warga masyarakat untuk menyatukan dirinya sebagai mahluk yang belum dewasa menjadi warga masyarakat secara penuh (Penalosa, 1980). Yang merupakan pusat sosialisasi yang menentukan adalah orang tua. Bahasa tidak hanya penting sebagai wahana sosialisasi, tetapi juga karena fungsinya sebagai objek yang harus dipelajari di seluruh proses kehidupan. Dengan demikian, bahasa menjadi wahana dan materi pembelajaran. Apabila dikaitkan dengan masalah sosial budaya, bahasa tidak hanya merupakan produk budaya tetapi juga alat budaya.

\section{Pemerolehan Bahasa}

Versi proses pemerolehan bahasa yang paling umum dan ekstrem adalah bentuk reduplikasi monosilabik menjadi : papa, mama, baba, untuk mengacu konsep tertentu (Dale, $1976: 8$ ). Mengoceh (meraban) pada tahap awal dan vokalisasi prelinguistik yang lain lazim diikuti oleh tuturan yang bermakna yang terdiri atas ujaran kata tunggal dan semuanya mendukung makna seluruh kalimat. Model demikian lazim dikategorikan sebagai bentuk tahap holofrastik (Bolinger, $1968: 5$ ). Tahap ini diikuti oleh ujaran yang terdiri atas dua kata yang dibatasi oleh kaidah sintaktik anak sendiri yang masih sangat sederhana. Bentuk demikian merupakan kreativitas anak di dalam proses pemerolehan bahasa. 
Apa yang membuat pemerolehan bahasa oleh anak-anak Jawa demikian menarik adalah konteksnya yang bilingual, dengan kemungkinan kedua bahasa digunakan di lingkungan keluarga (di rumah). Dapat juga dinyatakan secara lain, yakni bahasa Jawa dipelajari di numah dan bahasa Indonesia di tempat lain.

Seseorang belajar bahasa petamanya dari keluarga, dan teman dekat di dalam atmosfer : pembelajaran dan cara yang informal pada masa kanakkanak. Apabila bahasa kedua diperoleh dengan cara yang sama, kita tidak berhadapan dengan bahasa pertama dan kedua melainkan dengan dua bahasa. Ini berarti dua bahasa yang dipelajari secara simultan, tetapi pemerolehan bahasa yang satu tidak didasarkan atas konsep bahasa yang lain. Proses belajar ini berlangsung secara bebas tidak saling bergantung. Dalam hal ini kita berhadapan dengan fenomena pemilahan paduan yang koordinatif (Penalosa, 1980).

\section{Bahasa Jawa}

Pada umumnya di masyarakat Jawa yang berlaku sebagai bahasa ibu adalah bahasa Jawa. Itulah sebabnya masyarakat demikian dinamakan masyarakat tutur Jawa sebagai pendukung bahasa Jawa yang fungsional dan sekaligus sebagai bahasa daerah dan bahasa ibu bagi kebanyakan warga masyarakat ini.

Mengingat kedudukannya sebagai bahasa regional yang dengan serta-merta sebagai subordinat bahasa nasional, yakni bahasa Indonesia, tentu saja peran dan ruang geraknya lebih terbatas. Kepesatan perkembangan fungsi, status, dan peran bahasa Indonesia mengakibatkan kehadiran fenomena ketaksetaraan bahasa (periksa Wolson dan Manes, 1985).

Memperhatikan kondisi di atas, pada saat ini telah mulai terjadi pembatasan bahasa secara sosial yang dapat mengarah ke kondisi yang dinamakan kehilangan bahasa, dalam hal ini adalah bahasa Jawa. Padahal apabila diingat bahasa ini pada hakikatnya adalah bahasa pertama (bahasa ibu) masyarakat Jawa (periksa juga Garcia, 1995:144).

\section{Bilingualisme di Masyarakat Tutur Jawa}

Apabila diamati pada saat ini terdapat fenomena sosiolinguistik yang cukup menarik. Yang pertama dapat ditunjuk adanya bahasa ibu yang berupa bahasa Jawa dengan segala variasi dan kebiasaan pada keluarga 
penutur. Apabila demikian, yang terlihat adalah pemerolehan bahasa Jawa sebagai bahasa pertama (L1) dan secara dominan bahasa ini digunakan di antara teman, tetangga, atau anggota keluarga orang yang termasuk etnik yang sama, di dalam situasi yang informal dan emosional, atau pembicaaraan tentang topik yang dianggap tradisional (Poedjosoedarmo, 1981). Bahasa Indonesia berada di antara mereka sebagai bahasa kedua, yang penggunaannya terbatas pada lingkup formal seperti : sekolah, kantor, rapat resmi, dan pertemuan yang harus menggunakan bahasa Indonesia. Terdapat kemungkinan penggunaan Bahasa Indonesia terjadi pada saat terdapat interaksi dengan orang yang belum dikenal. Bahasa Indonesia merupakan bahasa kedua (L2) bagi model keluarga ini. Mereka menjadi penutur bilingual.

Di samping itu, terlihat fenomena terbalik. Suatu warga mengutamakan komunikasinya dengan bahasa Indonesia, baik di rumah maupun di luar rumah di antara mereka. Sejak memasuki usia pemerolehan bahasa, anak dalam keluarga tersebut menerima bahasa Indonesia sebagai bahasa pertama (L1). Fungsi bahasa ini menjadi lebih stabil karena selain dikembangkan di lingkup keluarga juga di sekolah dan di dalam komunikasi dengan orang lain baik yang dikenal maupun yang tidak dikenal. Anak-anak warga model keluarga seperti ini belajar bahasa Jawa dari subdomain kelompok bermain atau tetangga mereka. Model ini lazim ditemukan di kalangan keluarga muda masa kini atau generasi muda yang berpendapat bahwa bahasa daerah (Bahasa Jawa) kurang praktis oleh sebab kehadiran tingkat tutur di dalam bahasa ini. Terdapat kemungkinan keluarga demikian kurang menguasai tingkat tutur tersebut sebagai akibat perkembangan sosial budaya.

Selain itu, terdapat model pemerolehan bahasa dan proses bilingualisme yang berbeda dari kedua model sebelumnya. Di dalam model ini satu keluarga menggunakan kedua bahasa, yakni bahasa Jawa dan bahasa Indonesia dengan cara bergantian dan dalam proses pemerolehan bahasa anak mereka secara simultan. Model ini sangat jarang dan baru terekam di kalangan beberapa keluarga yang berdomisili di kota besar, seperti Yogyakarta, Semarang, Surabaya, Bandung, dan Jakarta. Tipe keluarga yang menerapkan pemerolehan bahasa demikian pada umumnya merupakan pendukung kebudayaan modern, tetapi masih berpretensi untuk melestarikan bahasa dan budaya Jawa. 
Apabila dicernati fenomena bilingualisme seperti yang terungkap di atas, mengikuti teknik pemilahan model proses pemerolehannya, dapatlah dibuat rangkumannya seperti di bawah ini.

a. Bahasa pertama (L1) : bahasa Jawa, bahasa kedua (L2) : bahasa Indonesia. Di sini terdapat pemisahan yang tegas dalam hal fungsi dan status bahasa. Bahasa pertama (L1) merupakan medium komunikasi informal, bahasa kedua (L2) sebagai medium komunikasi formal.

b. Bahasa pertama (L1): bahasa Indonesia, bahasa kedua (L2): bahasa Jawa. Bahasa pertama (L1) merupakan medium komunikasi informal dan formal, sehingga di sini lebih ditekankan di dalam pemilahan ragam bahasa. Bahasa kedua merupakan medium komunikasi informal dan intraetnis, serta dalam situasi yang emosional serta tradisional.

c. Bahasa Jawa dan bahasa Indonesia secara bergantian atau bersamaan dapat berfungsi sebagai medium komunikasi informal. Hanya di dalam komunikasi formal, pilihan jatuh pada bahasa Indonesia.

Dalam kaitan dengan ketiga fenomena tersebut, terlihat di sini bahwa peran subdomain keluarga sangat penting dan menentukan pembentukan model pemerolehan bahasa serta penggunaan bahasa. Di sana pula orang dapat mencatat motivasi belajar bahasa.

Mengamati model 3 orang dapat berasumsi bahwa di dalam keluarga yang demikian akan terjadi campur bahasa. Fenomena demikian merupakan akibat dari orang tua yang bilingual dan masyarakat yang bilingual, setiap orang tua dalam keluarga akan melakukan alih kode dan campur bahasa dengan anak-anak mereka (Edwards, 1995:63).

Domain pribadi yang semula benar-benar bilingual secara bertahap melakukan pergeseran. Pada awalnya mereka melakukan pergeseran metaforis di antara interlokutor dengan maksud memberikan tekanan atau kontras atas pesan atau topik, tidak dengan maksud menampilkan indikasi adanya situasi yang terputus. Selanjutnya teknik demikian dapat juga dilengkapi dengan pergeseran situasional. Para interlokutor melakukan pergeseran dari variasi yang satu ke variasi yang lain yang dapat mengisyaratkan adanya pergeseran di dalam hubungan sesama anggota suatu 
jaringan sosial, atau pergeseran topik atau maksud interaksi mereka. Apabila pergeseran dari bahasa yang satu ke bahasä yang lain acapkali terjadi dan makin kuat ke bahasa tertentu secara mantap, dapat diharapkan kondisi bilingual stabil akan menjadi bilingual takstabil (Fishman, 1972:4-10). Kenyataan demikian yang terjadi secara menerus dapat mengakibatkan suatu domain pribadi penutur bahasa ini menciptakan proses bilingual (ambilingual) menjadi monolingual penuturnya.

\section{Fungsionalisasi Bahasa}

1. Bahasa dan Kelompok Sebaya

Konteks belajar bahasa setelah lingkungan keluarga adalah kelompok sebaya yang merupakan konteks pemerolehan bahasa pada tingkat awal. Hanya pengaruh linguistik kelompok sebaya ini tidak dibatasi oleh kelompok bermain pada masa kanak-kanak. Pada tingkat usia ketika anakanak mulai bergerak dari standar dan nilai-nilai orang tua ke arah model kelompok sebaya, pada masa usia kanak-kanak tahap akhir atau bertepatan dengan masa remaja awal, norma-norma linguistik berubah juga (Penalosa, 1980 : 196). Dengan demikian, anak-anak mulai berbahasa mengikuti cara teman sebaya mereka, dan makin lama makin tidak seperti cara berbahasa orang tua dengan pola-pola yang diperoleh pada awal pemerolehan bahasa. Kondisi yang berupa kesenjangan generasi dan kesenjangan bahasa makin lebar terjadi. Sifat alami perbedaan semacam ini tergantung pada sifat alami setting sosial yang menjadi topik ini.

\section{Etnografi Bahasa}

Berbicara tentang pemgamatan atas realisasi bahasa di dalam interaksi, orang akan bersentuhan dengan apa yang lazim dinamakan etnografi bahasa. Di dalam jargon linguistik, etnografi bahasa dikatakan sebagai disiplin yang membuat deskripsi tentang bagaimana bahasa digunakan di dalam setting yang khas dengan maksud tertentu (Penalosa, $1980: 147)$.

Apa yang dikehendaki oleh seseorang dengan suatu tindak tutur tertentu tidak selalu identik dengan hasil tuturan yang diucapkan. Dalam kebiasaan yang sama kita dapat memilah bentuk dan fungsi bahasa. Bentukbentuk tertentu lazimnya digunakan untuk fungsi yang sama, meskipun bentuk-bentuk yang berbeda dapat juga digunakan untuk mengatakan fungsi 
yang sama, atau bentuk yang sama dapat mengekspresikan lebih dari satu fungsi selama bentuk demikian secara umum jelas dari konteks dan makna ujaran tepat, seperti yang dimaksudkan oleh fungsinya. Untuk memperjelas pernyataan di atas, berikut disertakan beberapa contoh.

1. Bentuk pernyataan sebagai perintah.

Kowe mesthi bisa ngewangi Bapak.

'Kamu pasti dapat membantu Bapak'.

2. Bentuk pertanyaan sebagai perintah. Apa kowe bisa nukokake buku adhimu?

'Apakah kamu dapat membelikan buku adikmu ?'

3. Bentuk pernyataan sebagai bentuk permintaan.

Aku butuh dhuwit kanggo tuku ban motor.

'Aku perlu uang untuk membeli ban motor.'

4. Bentuk pertanyaan sebagai larangan.

Kowe isih arep mangan pelem kecut iki?

'Kamu masih mau makan mangga masam ini ?'

5. Bentuk pernyataan sebagai larangan.

Awake dhewe ora kena ngrokok nang kene.

'Kita tidak boleh merokok di sini'.

Contoh no.1 s.d. no. 5 terasa sangat formal dan kurang bersifat aktual. Pada umumnya di dalam komunikasi sehari-hari pengguna tuturan lebih banyak memanfaatkan bentuk tuturan sebagai berikut, dengan arti yang sama.

1a. Kowe mesthi isa mbantu Bapak.

2a. Kowe bisa nukokke buku adhimu?

3a. Aku butuh dhuwit nggo tuku ban motor.

4a. Isih arep mangan pelem kecut iki?

5a. Awake dhewe ora oleh ngrokok neng kene.

Domain pribadi yang merupakan subdomain lingkungan keluarga ikut menentukan kebiasaan dan model kebahasaan penutur bahasa ini. Hal ini dapat dilihat pada beberapa penggunaan bahasa yang dilatarbelakangi oleh domain pribadi dalam kelas sosial tertentu. 
1. Keluarga Desa (Pelosok):

Simbok apa durung balik seka pasar?

'Tbu apakah belum pulang dari pasar ?'

2. Keluarga Kota Pinggiran

Mamak apa wis teka?

'Mamak apakah sudah datang ?'

3. Keluarga Keturunan Cina.

Ton, tacik arep lunga Semarang.

'Ton, kakak mau pergi ke Semarang'.

4. Keluarga Keturunan Arab.

Kae, umi wis teka.

'Itu, ibu sudah datang'.

5. Keluarga Priyayi Bangsawan

Ibu karo dhimas durung kondur.

'Tbu dan adik (lelaki) belum datang'.

6. Keluarga Muda (berpretensi modern)

$M a(h)$, papa(h) kok durung tindak?

'Bu, mengapa ayah belum berangkat ?'

Contoh yang dikemukakan merupakan bentuk yang berlaku di dalam interaksi verbal yang lazim. Dalam kaitan dengan ini tingkat tutur yang diinginkan adalah ngoko, baik ngoko lugu seperti pada contoh 1 s.d. 5 , dan contoh di bawah nomor 1 s.d. 4, maupun ngoko andhap (ngoko sae) seperti pada contoh di bawah nomor 5 dan 6 yang lazim di dalam sistem tingkat tutur dikategorikan sebagai antya basa dan basa antya (Poedjosoedarmo, 1979 : 9).

\section{Kesimpulan}

Mengikuti pembicaraan di atas dapatlah ditarik kesimpulan sementara sebagai di bawah ini. 
1. Domain pribadi merupakan lingkungan pembentuk kompetensi dan performansi bahasa, sikap penutur bahasa Jawa, dan ikut menentukan kadar sikap serta perilaku kebiasaan berbahasa seseorang.

2. Kondisi penguasaan bahasa seseorang juga mendapat pengaruh dari ekologi bahasa, yakni apakah seseorang menjadi penutur monolingual atau bilingual.

3. Dalam kaitan dengan pemerolehan bahasa, pembelajaran selalu disertai proses sosialisasi, yakni bagaimana bahasa itu berfungsi dalam kehidupan sosial.

4. Sebagai penutur yang bilingual, warga masyarakat tutur ini dapat dibedakan menjadi tiga kategori, yakni (1) kelompok dengan pemilahan bahasa ibu (L1) bahasa Jawa dan bahasa kedua (L2) : bahasa Indonesia, masing-masing dengan fungsi sebagai medium komunikasi informal dan formal, (2) kelompok dengan bahasa ibu (L1) bahasa Indonesia dan bahasa kedua (L2) bahasa Jawa. Bahasa ibu sebagai medium komunikasi informal dan formal, di sini lebih ditekankan pada pemilahan ragam bahasa. Bahasa kedua merupakan medium komunikasi intraetnis, serta dalam situasi yang emosional dan tradisional; (3) kelompok dengan bahasaa Jawa dan bahasa Indonesia yang berfungsi secara bergantian atau bersamaan sebagai medium komunikasi informal. Di dalam komunikasi formal, pilihan jatuh pada bahasa Indonesia.

5. Fakta yang ditemukan berupa bilingualisme dan ketaksetaraan bahasa dengan kedudukan dan peran bahasa Indonesia yang lebih dominan, mengundang fenomena sosiolinguistik dalam bentuk pergeseran metaforis, pergeseran situasional, bilingual stabil dan bilingual takstabil, interferensi, alih kode dan campur bahasa.

6. Penguasaan bahasa Jawa yang semakin melemah sebagai akibat (5) menyebabkan kehadiran penyederhanaan tingkat tutur dengan asas dikotomis, yakni ngoko dan basa termasuk madya dan krama (inggil). Fenomena demikian merupakan akibat ketidakmampuan memilah tingkat tutur menjadi ngoko - madya - krama.

7. Berbagai kemungkinan bentuk dan fungsi bahasa terlihat di dalam etnografi bahasa sebagai keluaran peran domain pribadi. 


\section{DAFTAR PUSTAKA}

Bolinger, Dwight. (1968). Aspects of Language . New York : Harcourt, Brace \& World Inc.

Dale, Philips. S. (1976). Language development. Second edition. New York : Holt Reinhart and Winston.

Edwards, John (1995). Multilingualism. London : Penguin Books Ltd.

Fishman, Joshua (1972) Language in sociocultural change. dalam A.S. Dill(ed). California : Stanfod Universitiy Press.

Garcia, Ofelia. (1995). Spanish language loss as a determinant of income Latinos in the United States, dalam j. W. Tollefson (ed) : Power and inequality in language education. Cambridge University Press.

Holmes, Janet, (1995). An Introduction to sociolinguistics. London : Longman.

Langgole, Nurdin. (1993). Ekologi bahasa Indonesia di Kotamadya Ujung Pandang, dalam Penyelidikan bahasa dan perkembangan wawasannya. Jakarta : Masyarakat Linguistik Indonesia.

Penalosa, Fernando (1980). Chicano Sociolinguistics. A brief introduction. Massachusetts : Rowley.

Poedjosoedarmo, Soepomo. (1979). Tingkat tutur bahasa Jawa. Jakarta : Pusat Pembinaan dan Pengembangan Bahasa.

Poedjosoedarmo, Soepomo. (1981). Problems of Indonesian dalam Amran Halim (ed). Bahasa dan Pembangunan Bangsa. Jakarta : Pusat Pembinaan dan Pengembangan Bahasa.

Walson, Nessa dan Joan Manes (1985). Language of inequality. New York : Mouton. 